\title{
A Construção de Garantias para o Direito de Acesso e a Esfera do Ambiente ${ }^{1}$
}

\author{
The Construction of Guarantees for the Right of Access and the Sphere of the \\ Environment
}

Sergio Urquhart de Cademartori

Universidade de Caxias do Sul, Caxias do Sul-RS, Brasil

Caroline Ferri

Universidade de Caxias do Sul, Caxias do Sul-RS, Brasil

Resumo: Este artigo busca analisar a questão do segredo como um instrumento de poder político que acompanha a história política dos Estados, destacando-se, para tanto, a sua caracterização nos chamados Estados democráticos de direito a partir da questão da transparência nas esferas administrativa e ambiental. Para tanto, serão utilizados os conceitos de segredos de Estado como aquelas informações que devem ser mantidas ocultas do público em geral em contrapartida com a chamada esfera de necessidade de divulgação de todos os atos e políticas governamentais próprias do regime democrático, a fim de que se possa evitar a formação de instrumentos de dominação popular.

Palavras-chave: Direito de Acesso. Segredos de Estado. Acesso Ambiental.
Abstract: This paper aims at analyzing the issue of secrecy as an instrument of political power that accompanies the political history of the States, highlighting their characterization in so-called democratic States of law from the issue of transparency in administrative and environmental spheres. For this, we will use the concepts of State secrets, defined as those pieces of information that must be kept hidden from the general public in contrast with the so-called need for disclosure of all government acts and policies that pertain to democratic systems, so that the formation of instruments of popular domination can be prevented.

Keywords: Right of Access. State Secrets. Environmental Access.

Recebido em: 22/08/2013

Revisado em: 06/11/2013

Aprovado em: 11/11/2013 


\section{Introdução}

O segredo como prática de dominação política, ou como instrumento de poder ${ }^{2}$, acompanha a trajetória histórica do Estado. Corporificada hoje na noção de "segredos de Estado", a ação do governo que se oculta ocultando suas práticas, encontra-se presente nas reflexões de quase todos aqueles que erigem a política como campo privilegiado de estudo. De fato, desde o nascedouro daquela instituição conhecida como "forma-Estado", atravessada por um lento processo de laicização do poder a partir da Baixa Idade Média Ocidental e a subsequente consolidação de governos absolutistas, se encontram práticas secretas dos governantes no centro dos processos de tomada de decisão a respeito do destino de seus subordinados.

Neste ensaio, busca-se analisar o percurso que o tema teve através do pensamento de alguns autores do campo político-jurídico, a fim de enquadrá-lo, em momento posterior, no Estado Democrático de Direito, a partir de um enfoque garantista. Tenta-se, assim, verificar de que forma o segredo imbrica-se ou encontra guarida em suas instituições, práticas e valores, e as possibilidades de sua sobrevivência em um regime democrático, seja através de legislações restritivas do acesso a ações e documentos, seja esclarecendo as práticas secretas do Estado que podem apresentar-se como benéficas.

Por último, debruça-se o ensaio de forma meramente aproximativa sobre a nova Lei brasileira de Acesso às informações governamentais, enfatizando o avanço que a ela representa na conquista da transparência administrativa geral e na esfera do ambiente.

De tal modo, parte-se do pressuposto de que a transparência do agir estatal - corporificada no princípio/dever de publicidade da administração, reflexo do direito fundamental de acesso das pessoas às informações

2 Adota-se aqui uma definição relacional de poder. De acordo com Bobbio (1987, p. 78): “A mais conhecida e também a mais sintética das definições relacionais é a de Robert Dahl: 'A influência [conceito mais amplo, no qual se insere o de poder] é uma relação entre atores, na qual um ator induz outros atores a agirem de um modo que, em caso contrário, não agiriam"”. (1963, trad. it., p. 68) 
pessoais e de interesse público - apresenta-se como elemento indispensável à democracia como prática governamental cotidiana. Portanto, trata-se de analisar a tensão entre segredo e Estado de Direito, enfocando ao final a trajetória normativa que o direito fundamental de acesso percorre em nosso ordenamento democrático.

Com essa finalidade, por segredos de Estado entender-se-á aqui todo conhecimento, informação ou ação que, por ter em vista a manutenção da dominação, é destinada pelos detentores do poder do Estado a manter-se oculta do público.

De outro lado, entender-se-á por Estado de Direito - na esteira das definições de Bobbio e Ferrajoli (1995) - a estrutura jurídico-política de dominação marcada por duas características básicas, sem as quais, independentemente das variações que tal artifício possa adotar, não será possível falar em Estado de Direito: a) de um lado, trata-se de um poder que age per leges, isto é, um governo que manifesta sua vontade através de normas gerais e abstratas (isso perfaz o aspecto formal do Estado de Direito); b) de outro lado, este é um poder sub lege, é dizer, submetido ao direito em dois sentidos: b1) em sentido fraco, lato ou formal, significa que nele todo poder é conferido ou atribuído pelo direito; e b2) em sentido estrito, forte ou substancial, significa que ali todo poder é limitado pelo direito.

\section{A Razão de Estado, o "Segredo do Cargo" e a Democracia}

Já no século XX é possível encontrar em Carl Schmitt (1968) uma aguda análise do segredo de Estado a partir de seus fundamentos teórico-políticos. Diz ele que a partir do esgotamento da visão teológica e patriarcalista do nascimento do reino dos homens, no século $\mathrm{XV}$, a política passou a desenvolver-se como ciência, sendo que o conceito básico dessa nova ciência é a Razão de Estado ${ }^{3}$. Num grau ainda mais elevado, que

\footnotetext{
3 Este conceito também pode ser entendido como a tradição doutrinária que “[...] afirma que a segurança do Estado é uma exigência de tal importância que os governantes, para garantir, são obrigados a violar normas jurídicas, morais, políticas e econômicas que consideram imperativas quando essa necessidade não corre perigo. Por isso, [...] os
} 
o conceito de Razão de Estado, encontra-se, na literatura surgida nesse período, o conceito de arcanum político; e "[...] el concepto de arcanum político y diplomático, incluso allí donde significa secretos de Estado, no tiene ni más ni menos de místico que el concepto moderno de secreto industrial y secreto comercial [...]". Consequentemente, isso "[...] demuestra el simple sentido técnico del arcanum: es un secreto de fabricación". (SCHMITT, 1968, p. 45)

Transcrevendo a análise de Arnold Clapmar (1574-1604), Schmitt assevera ainda que cada ciência tem seus arcana e todas utilizam meios ardis para atingir seus fins, embora no Estado sempre sejam necessárias certas manifestações de liberdade para tranquilizar o povo (simulacra, instituições decorativas); é assim que os arcana reipublicae são as verdadeiras forças propulsoras internas do Estado (o que move a história universal não são quaisquer forças econômicas ou sociais, mas “[...] el cálculo del Príncipe y su Consejo secreto de Estado, el plan bien meditado de los gobernantes, que tratan de mantenerse a sí mismos y al Estado, [...]" (SCHMITT, 1968, p. 45). Já dentro dos arcana, é de se distinguir os arcana dominationis, pois se os arcana imperii referem-se às diversas técnicas para manter o povo tranquilo (certa participação nas instituições políticas, liberdade de imprensa, de manifestações etc.), os arcana dominationis referem-se à proteção e defesa das pessoas que exercem a dominação durante acontecimentos extraordinários, rebeliões e revoluções, e os meios empregados para sair-se bem nessas circunstâncias. Finalmente, os arcana são "[...] planes y prácticas secretos, con cuya ayuda son mantenidos los jura imperii [...]", sendo estes por sua vez diferentes direitos de soberania, especialmente o direito de promulgar leis. (SCHMITT, 1968, p. 45-49, grifos nossos)

Pelo que se percebe, o segredo de Estado é tratado por Schmitt como um conhecimento científico inacessível aos não iniciados, tendo em vista a manutenção do status quo. De outra parte, pela transcrição que ele

governantes dos Estados não devem descurar nenhum meio - mesmo o da mais despiedada violência e do engano - para atingir [seus fins]. [...] Pense-se na diplomacia secreta, nos segredos de Estado [...] que constituem uma violação latente dos princípios democráticos mais comuns, mas que, não obstante, sempre foram e continuam sendo prática constante nos Estados democráticos. (PISTONE, 1986, p. 1.066-1.073) 
faz das teorias de Clapmar, nota-se que o que está subjacente a esta doutrina é uma visão conspiratória da História (a História é feita por poucos privilegiados: o Príncipe e seus conselheiros são o deus ex machina da História, não as forças sociais). E mais ainda, a praxis de governar é vista aí como ciência, atualizando a rica tradição surgida com Maquiavel.

De seu lado, Max Weber (1984), ao analisar a "sociologia da dominação", abre um parágrafo específico para referir-se à dominação através da "organização", vista por ele como a estrutura social permanente para fins de governo. Esse tipo de dominação está embasado na "vantagem do pequeno número" ([...] es decir, en la posibilidad que tienen los miembros de la minoría dominante de ponerse rápidamente de acuerdo y de crear y dirigir sistemáticamente una acción societaria racionalmente ordenada a la conservación de su posición dirigente.) (WEBER, 1984, p. 704). E o valor dessa vantagem repousa justamente na possibilidade da manutenção do segredo ${ }^{4}$.

Assim, no centro desse moderno tipo de dominação encontra-se o mecanismo do segredo, da ocultação. O segredo, conforme Weber, constitui-se num importante mecanismo de poder no cerne de qualquer estrutura burocrática. Observe-se, a respeito, a seguinte passagem:

Toda burocracia procura incrementar esta superioridad del saber profesional por medio del secreto de sus conocimientos e intenciones. El gobierno burocrático es, por su misma tendencia, un gobierno que excluye la publicidad. La burocracia oculta en la medida de lo posible su saber y su actividad frente a la crítica. (WEBER, 1984, p. 744)

\footnotetext{
4 “'La 'ventaja del pequeño' número adquiere su propio valor por la ocultación de las propias intenciones por las firmes resoluciones y saber de los dominantes. Todo esto se hace más difícil e improbable a medida que aumenta su número. Todo aumento del 'secreto del cargo' constituye un síntoma de la intención que tienen los dominadores de afirmarse en el poder o de su creencia en la amenaza creciente que se cierne sobre el mismo. Toda la dominación que pretenda la continuidad es hasta cierto punto una dominación secreta". (WEBER, 1984, p. 704)

5 E adiante, ao tratar da publicidade administrativa, pondera: “[...] la mayor fuerza del funcionalismo consiste en la conversión, a través del concepto del 'secreto profesional',
} 
Para Norberto Bobbio (1983), o segredo de Estado constitui-se num dos principais obstáculos para a implementação de uma Democracia plena. Parte ele da ideia de que atualmente o Estado apresenta aspectos de representatividade ampliada que superam a concepção original do Estado representativo clássico, moldado na ideia britânica da existência de um parlamento que corporificaria os interesses da sociedade ${ }^{6}$. Assim, o segredo é característica importante daquilo que Bobbio considera como "Estado administrativo", que é o conjunto de aparelhos administrativos centralizados e centralizadores.

O autor concorda com a afirmação de que a Democracia é o governo do poder visível. E, ainda, que a Democracia é o governo do poder público em público, já que a palavra "público" pode assumir dois significados: não privado e não secreto (BOBBIO, 1986, p. 83-84). Recorda, ainda, que a visibilidade como inerente ao regime democrático vem da reunião dos cidadãos atenienses congregados na ágora ou na eclesia, em que todos os problemas inerentes à cidade eram debatidos à luz do dia. (BOBBIO, 1986, p. 84)

Como prova da sobrevivência da ideia da publicidade como constitutiva do regime democrático, traz Bobbio para a colação uma passagem de Michele Natale, bispo de Vico, no tempo da Revolução Francesa:

[...] não existe nada de secreto no regime democrático? Todas as operações dos governantes devem ser reconhecidas pelo povo soberano exceto algumas medidas de segurança pública, que ele deve conhecer apenas quando cessar o perigo. (MICHELE NATALE apud BOBBIO, 1986, p. 86) ${ }^{7}$

del saber relativo al servicio en un saber secreto, o sea en un medio, en última instancia, para asegurar a la administración contra los controles”. (1984, p. 744)

6 Tome-se, para exemplificar, o seguinte trecho: “Aquilo que nós, para resumir, chamamos estado representativo teve sempre que se confrontar com o Estado administrativo, que é um Estado que obedece a uma lógica de poder completamente diferente, descendente e não ascendente, secreta e não pública, hierarquizada e não autônoma, pendente ao imobilismo e não dinâmica, conservadora e não inovadora etc.” (BOBBIO, 1983, p. 72) grifo acrescentado.

7 E continua Bobbio: Este pequeno trecho é exemplar porque enuncia em poucas linhas um dos princípios fundamentais do estado constitucional: o caráter público é regra, o 
Não é apenas o Estado Constitucional ou o Estado de Direito que deve ter a publicidade como regra, mas muito mais o Estado Democrático de Direito, que é definido por ele como "[...] o governo direto do povo ou controlado pelo povo (e como poderia ser controlado se se mantivesse escondido?)". (BOBBIO, 1986, p. 87)

Dessa forma, o autor acrescenta mais uma característica à sua definição procedimental de Democracia, a qual contempla a resposta à pergunta: quem controla o poder (o quid custodies custodiet dos romanos)? A publicidade entra aí como elemento fundamental para possibilitar esse controle pelo povo e seus representantes. A publicidade é fundamental para estabelecer distinção entre o regime absolutista e o constitucional "[...] e, assim, para assimilar o nascimento ou renascimento do poder público em público". (BOBBIO, 1986, p. 87)

$\mathrm{E}$, na atualidade, a publicidade torna-se imperiosa, eis que o controle dos súditos por parte do Estado se faz mais total a cada dia ${ }^{8}$. E é por isso que o autor destaca o poder invisível, junto à privatização do público e à ingovernabilidade, como os três aspectos notórios da crise da Democracia. (BOBBIO, 1985, p. 5-25)

Em outra obra (BOBBIO, 1988, p. 208), ainda, redefinindo a sua noção de Democracia como idealmente "[...] o governo do poder visível, ou o governo cujos atos se desenvolvem em público, sob o controle da opinião pública [...]", ele revela os mecanismos que o poder autocrático (e, como já referido, também o Estado administrativo) se utiliza para escapar ao olhar da opinião pública: ocultando-se e ocultando 9 .

segredo a exceção, e mesmo assim é uma exceção que não deve fazer a regra valer menos, já que o segredo é justificável apenas se limitado no tempo [...].

8 A medida que aumenta la capacidad del estado para controlar los ciudadanos debería aumentar la capacidad de los ciudadanos para controlar al estado. Pero este crecimiento paralelo está muy lejos de verificarse. Entre las diversas formas de abuso del poder está, actualmente la posibilidad, por parte del estado, de abusar del poder de información [...]. (BOBBIO, 1985, p. 24)

9 O poder autocrático foge do controle público de duas maneiras: ocultando-se, ou seja, tomando suas próprias decisões no ‘conselho secreto' e ocultando, ou seja, através do exercício da simulação e da mentira, considerada como instrumento lícito de governo. (BOBBIO, 1988, p. 208) 
No mesmo ensaio, ao estabelecer uma tipologia das formas de poder invisível, Bobbio resume-as em três: um poder invisível dirigido contra o Estado (máfias, grupos terroristas, etc.); um segundo tipo de poder invisível que age à sombra do Estado (associações secretas como a Loja Maçônica P-2, por exemplo); e

[...] finalmente, o poder invisível como instituição do Estado: os serviços secretos, cuja degeneração pode dar vida a uma verdadeira forma de governo oculto. Que todos os Estados tenham seus serviços secretos é um mal, diz-se, necessário. Ninguém ousa por em dúvida a compatibilidade do Estado democrático com o uso dos serviços secretos. Mas estes são compatíveis com a democracia apenas num contexto: que sejam controlados pelo governo, pelo poder visível, que por sua vez deve ser controlado pelos cidadãos, de modo que sua ação seja dirigida sempre e apenas para a defesa da democracia. (BOBBIO, 1988, p. 210-211)

A esta última forma de poder secreto é que se dá relevo no presente trabalho, pois o que interessa aqui é justamente tentar rastrear as relações entre o poder oculto exercido pelo Estado e a Democracia. Assim, se entende a Democracia como "poder visível", no sentido ampliado que ora lhe dá o autor, vê-se que a vitória desse poder sobre o poder invisível "[...] jamais se completa plenamente: o poder invisível resiste aos avanços do poder visível, inventa modos sempre novos de se esconder e de esconder, de ver sem ser visto". Por isso, a dicotomia público/privado, no sentido de manifesto/secreto, é para ele

[...] uma das categorias fundamentais e tradicionais, mesmo com a mudança dos significados, para a representação conceitual, para a compreensão histórica e para a enunciação de juízos de valor no vasto campo percorrido pelas teorias da sociedade e do Estado. (BOBBIO, 1987, p. 30-31)

Hannah Arendt, filósofa que assume a dignidade humana como uma de suas preocupações fundamentais, brilhante analista do fenômeno totalitário, também tratou do segredo e suas relações com sociedades e regimes democráticos ou não. De fato, encontram-se esparsas em várias obras 
suas referências ao fenômeno do segredo como prática política, dado que, para ela, a visibilidade é parte imprescindível do espaço político ${ }^{10}$.

A preocupação da filósofa com a transparência e a verdade no espaço público torna-se quase obsessiva, acompanhada de uma indignação genuinamente moral com uma prática que ela reconhece e que faz parte da história política do Ocidente:

El sigilo - que diplomáticamente se denomina "discreción", así como los arcana imperii, los misterios del Gobierno - y el engaño, la deliberada falsedad y la pura mentira, utilizados como medios legítimos para el logro de fines políticos, nos han acompañado desde el comienzo de la Historia conocida. La sinceridad nunca ha figurado entre las virtudes políticas y las mentiras han sido siempre consideradas en los tratos políticos como medios justificables. (ARENDT, 1973, p. 12)

Ao tentar uma explicação psicológica para isso, a autora suspeita que "Puede que sea natural que quienes ocupan cargos electivos [...] piensen que la manipulación es quien rige las mentes del pueblo, y, por consiguiente, quien rige verdaderamente al mundo." (ARENDT, 1972, p. 26). Assim, ela crê que os governantes possam ter uma visão conspiratória da política, o que tenta demonstrar, com um exame sociológico do caso dos Pentagon Papers durante a administração Nixon nos EUA. (ARENDT, 1972)

Mas, o verdadeiro triunfo do segredo e da manipulação sobre a livre circulação de ideias no espaço público dá-se quando ele é abolido: sob um sistema totalitário. É aqui que o segredo faz "metástase", abrangendo em sua totalidade as esferas do poder. Em sua análise sobre o totalitarismo, diz Arendt (1978): durante a fase de ascensão ao poder dos

10 Se a função do âmbito público é iluminar os assuntos dos homens, proporcionando um espaço de aparições onde podem mostrar, por atos e palavras pelo melhor e pelo pior, quem são e o que podem fazer, as sombras chegam quando essa luz se extingue por 'fossos de credibilidade' e 'governos invisíveis', pelo discurso que não revela o que é, mas o varre para sob o tapete, com exortações morais ou não, que, sob o pretexto de sustentar antigas verdades, degradam toda uma trivialidade sem sentido (ARENDT, 1987, p. 8). No mesmo sentido, ver Arendt (1972, p. 293). 
movimentos totalitários, estes imitam algumas características de organização das sociedades secretas; quando chegam ao poder, "se instalam à luz do dia", criando uma "verdadeira sociedade secreta": a polícia secreta, (ARENDT, 1978, p. 542) que assume o papel de Estado dentro do Estado $^{11}$. Para Arendt, o segredo é o mecanismo central, a pedra de toque da ação política nos regimes totalitários ${ }^{12}$.

Em contrapartida, o acesso às informações governamentais numa Democracia é parte inseparável da prática política, como meio de controle do poder por parte dos governados, da conduta dos governantes ${ }^{13}$. A publicidade é, para Arendt (1978, p. 530) a pré-condição para que se possa até mesmo falar em política, já que a política é definida pela autora como "[...] o campo de comunicação e de interação que assegura o poder do agir conjunto". O que implica concluir-se que, sob regimes totalitários, desaparece toda e qualquer possibilidade de ação política, tomada nesse sentido; trata-se de um conjunto de práticas de pura dominação. (LAFER, 1988, p. 245)

Há ainda em Arendt uma reflexão sobre a importância prática da manutenção do princípio da publicidade na esfera pública. Como relata Lafer (1988, p. 256):

Com efeito, na esfera do público, entendida como o comum, os enganados pela mentira reagem aos enganadores minando a comuni-

\footnotetext{
11 Os serviços secretos já foram rotulados corretamente de um Estado dentro do Estado, e isso não se aplica apenas aos despotismos, mas também aos governos constitucionais e semiconstitucionais. A simples posse de informações secretas sempre lhes deu nítida superioridade sobre todas as outras agências do serviço público, e constituiu franca ameaça aos membros do governo. (ARENDT, 1978, p. 530)

12 Nas palavras de Celso Lafer (1988, p. 242), Hannah Arendt tem uma percepção muito clara da relevância do direito à informação como meio para se evitar a ruptura totalitária. Com efeito, uma das notas características do totalitarismo é a negação, ex parte principis, da transparência na esfera pública e do princípio da publicidade [...].

13 "É por essa razão que, no mundo moderno, a representação política democrática, que substitui a ágora da polis, só pode ter lugar na esfera do público, e um Parlamento só pode ser representativo, como aponta Carl Schmidt, se existe a crença de que sua atividade específica reside na publicidade. Neste sentido, numa democracia a publicidade é a regra básica do poder e o segredo a exceção, o que significa que é extremamente limitado o espaço dos arcana imperii, ou seja dos segredos de Estado". (LAFER, 1988, p. 243-244)
} 
dade política. É por isso que a prevalência ex parte principis dos arcana imperii provoca, dialeticamente, os arcana seditionis ex parte populi. Estes também são destrutivos do espaço público da democracia, pois podem levar à ditadura anônima dos grupos terroristas clandestinos, que também se valem da mentira e da dissimulação, cientes da clássica lição de MAQUIAVEL: Se poucos podem travar uma guerra aberta contra o poder autocrático, a todos é dado conspirar em sigilo contra o Príncipe. Poder invisível e contrapoder invisível são, em verdade, duas faces da mesma moeda.

Enfim, o que se ressalta das obras arendtianas citadas é uma preocupação com a ética no espaço público, reivindicando para a prática política uma dimensão moral que muitos autores de ciência política insistem em subtrair.

No Brasil, é possível encontrar preocupação com o tema em poucos autores, dentre os quais ressalta João Almino (1986). Para ele, existem segredos fabricados a partir do poder do Estado contra a publicização do espaço privado, contra os quais o único antídoto é a ausência de censura. Diz o autor que o segredo, além de dominante como prática política nos regimes não democráticos, é também peça importante dentro das democracias, como estratégia governamental. Adotando uma perspectiva kantiana, entende que a publicidade deve prevalecer sempre, como imperativo categórico da política não importando os motivos ou objetivos para sua exclusão. Mas isso somente valeria para uma Democracia "sem adjetivos", "[...] pois uma democracia adjetivada teria que por algum fim acima dos meios - e o segredo e a mentira seriam apenas meios". (ALMINO, 1986, p. 13-16)

O autor é enfático ao asseverar que "[...] nenhuma 'causa nobre' definida de maneira técnica pelo Estado, pode legitimar o uso do segredo" (ALMINO, 1986, p. 17-18). A constituição de uma esfera pública política legitimamente democrática torna-se, para ele, tarefa a ser construída pela sociedade ${ }^{14}$.

14 Só a prática política poderá fazer o segredo de Estado desvendar-se ante o direito à informação. O sujeito do direito à informação é o cidadão. [...] O direito à informação, seja exercido pelo jornalista ou por qualquer cidadão, não deve sofrer formalmente restrições 
A preservação dos segredos visa a subtrair o governo ao controle dos cidadãos como forma de se evitar o julgamento de suas ações pela sociedade, ao passo que cria um saber circunscrito a poucos visando o exercício de um poder exclusivo. Para ele, as razões invocadas pelos Estados "protetores" para manter o povo na ignorância de suas ações, são as de que essa prática impediria a corrupção do povo, bem como o protegeria do inimigo. Ele alcunha essas práticas de "paternalismo elitista autoritário”. (ALMINO, 1986, p. 17-18)

O autor ressalva expressamente que em alguns casos a preservação do segredo possa ser entendida como legítima ${ }^{15}$. Mas essa legitimidade deve ser negociada socialmente, como pré-condição de sua aceitação pela sociedade (ALMINO 1986, p. 100). Assim, a questão central em relação ao tema dos segredos de Estado versa sobre a autolimitação pela sociedade de seu direito à informação partindo da discussão prévia sobre os casos - circunscritos e bem delimitados - nos quais deve prevalecer o segredo. A partir dessa discussão, é necessário estabelecer critérios rígidos para a preservação de sigilo, o qual, nunca é demais lembrar, acompanhando Bobbio, deve ser sempre exceção que não faça a regra valer menos.

\section{O Direito de Acesso como Direito Fundamental e a Aborda- gem Garantista da Transparência}

Com a consolidação da democracia constitucional nos países ocidentais, o direito a ser informado passa a constituir-se em direito fundamental, em cumprimento ao disposto no artigo 19 da Declaração Universal dos Direitos Humanos (o direito "to receive information"16). No

de qualquer natureza, embora na prática possa curvar-se ante o segredo empiricamente aceito como legítimo. (ALMINO, 1986, p. 17-18)

15 Embora o autor não apresente seu conceito de "legitimidade", infere-se do texto que ela pode ser entendida como "adequação" da ação estatal aos valores da sociedade". Vejase, por exemplo, “[...] a própria sociedade aceitará os limites a seu direito à informação se estes forem legítimos". (ALMINO, 1986, p. 100)

16 Art. 19: Todo ser humano tem direito à liberdade de opinião e de expressão; esse direito inclui a liberdade de ter opiniões sem sofrer a interferência e de procurar, receber e divulgar informações e ideias por quaisquer meios, sem limite de fronteiras". 
mesmo sentido, o artigo 19 do Pacto Internacional sobre direitos civis e Políticos, o art. 13 da Convenção Interamericana sobre Direitos Humanos, o artigo 9 da Carta Africana sobre os Direitos Humanos e dos Povos e o artigo 10 da Convenção Europeia sobre Direitos Humanos ${ }^{17}$.

Em reforço a essa tendência, os Relatores para a Liberdade de Expressão da ONU, OEA e OSCE, em sua Declaração conjunta de 2004, enfatizaram que:

O direito de acessar informações detidas pelas autoridades públicas é um direito humano fundamental que deve ser efetivado no nível nacional através de legislação abrangente (por exemplo, leis específicas sobre liberdade de informação), baseada na premissa da máxima abertura, estabelecendo a presunção de que toda informação é acessível, sujeita apenas a um restrito sistema de exceções. (CANELA; NASCIMENTO, 2009, p. 19)

Refletindo esse movimento internacional pela democratização do acesso às informações governamentais, a ONG Artigo $19^{18}$ consolidou em 1999 os princípios que devem reger a política de transparência dos governos, sendo eles os seguintes:

a) Princípio da máxima divulgação, que estabelece a premissa de que toda a informação mantida por organismos públicos deve estar sujeita à divulgação e de que tal suposição só deverá ser superada em circunstâncias muito limitadas.

b) Princípio da obrigação de publicar, pelo qual os órgãos e entidades públicas devem espontaneamente publicar as informações e documentos que possuam importância pública ${ }^{19}$.

\footnotetext{
17 Em 2008, mais de 70 países haviam adotado leis de acesso à informação. (MENDEL, 2008, p. 3)

18 Que tem a seguinte definição para o termo informações públicas: "Todos os dados e registros em poder de órgãos públicos, com a identificação da fonte (quem produziu o dado ou registro) e da data em que foi produzido. Esses dados incluem todo e qualquer formato: documento impresso ou eletrônico, vídeo, áudio etc."

19 Essas informações devem no mínimo ser as seguintes:

b.1) Informações sobre a operação da entidade ou órgão;

b.2) Informações sobre solicitações ou queixas a ele relacionadas;
} 
c) Princípio da promoção de um governo aberto, o que inclui desde educação pública sobre esse novo ethos até o treinamento de pessoal para esclarecimento da política de transparência.

d) Princípio do âmbito limitado das exceções, pelo qual estas devem ser clara e rigorosamente desenhadas e sujeitas a rígidas provas de "dano" e "interesse público". Estas provas foram construídas pela jurisprudência internacional e consolidadas num mecanismo chamado de "três fases". Este visa a avaliar a relação custo (dano)/benefício (atendimento ao interesse público) na divulgação de dados em cada caso concreto ${ }^{20}$.

e) Processos para facilitar o acesso: os pedidos devem rapidamente ser atendidos, com órgão recursal para analisar eventuais indeferimentos, bem como a preservação da reserva judicial de garantia.

f) Custos. Os custos excessivos não podem tolher o direito de acesso.

g) Reuniões abertas. As reuniões de organismos públicos devem ser públicas.

h) Princípio da primazia da divulgação, por força do qual as leis antinômicas ao princípio da máxima divulgação devem ser alteradas ou revogadas.

i) Princípio da proteção de denunciantes: todos aqueles que divulguem (denunciem) irregularidades devem ser protegidos.

Como se pode notar, esse esforço de organismos internacionais está inserido no novo zeitgeist instaurado pela disseminação do modelo de Estado Democrático de Direito, que centra suas funções nos direitos funda-

b.3) orientações sobre como deve o cidadão proceder para participar com sugestões sobre o órgão e seu funcionamento;

b.4) Tipo de informação depositada no órgão; e

b.5) Conteúdo das decisões que atinjam o público externo, bem como suas motivações.

20 A manutenção do sigilo num determinado caso só pode ser legítima se os seguintes três requisitos forem satisfeitos:

d.1) a informação solicitada se relaciona a um dos objetivos legais;

d.2) a divulgação da informação cause graves danos; e

d.3) o prejuízo (custo) trazido pela divulgação possa ser maior que o benefício (interesse público) implicado por ela. 
mentais das pessoas, com a consequente accountability de seus órgãos e entidades.

Tal circunstância leva inexoravelmente a analisar a partir de um viés garantista esse direito, já que se entende aqui que o garantismo é a teoria do Estado e do Direito que dá conta de forma mais adequada da estrutura e da função da forma política do Estado Constitucional de Direito. Empreende-se essa análise examinando as reflexões do grande teórico do garantismo, Luigi Ferrajoli, hoje o principal jusfilósofo italiano.

Para Ferrajoli (2007, p. 419), a informação constitui o objeto de dois direitos distintos: o direito de informação como direito ativo de liberdade (denominado por ele de liberdade de ou faculdade)(2007, p. 336337) e como direito social passivo consistente em uma expectativa positiva (direito $a$ receber informações).

Restringindo a análise a esse segundo sentido - o direito a receber informações - verifica-se que trata-se de um direito autônomo e coletivo que pertence a todos e a cada um simultaneamente (FERRAJOLI, 2007, p. 419). Por isso, esse direito requer explícitas garantias constitucionais (sendo as garantias primárias as obrigações dos poderes públicos de prestar as informações, e as garantias secundárias a possibilidade de exigi-las em juízo, ou seja, a sua justiciabilidade).

Explicitando seu pensamento, Ferrajoli (2007, p. 420) divide a transparência pública em duas dimensões: Em primeiro lugar, ex parte principis, a transparência dos poderes públicos e a informação sobre a sua gestão são uma precondição elementar da democracia, e mesmo antes disso, do direito público (recorda ele a fórmula transcendental do direito público kantiana).

Em segundo lugar, ex parte populi, a informação relativa aos assuntos públicos é a condição necessária para o exercício do direito de voto consciente (isto é, com total conhecimento) (FERRAJOLI, 2007, p. 420). Em reforço, evoca a passagem de Tocqueville na qual ele afirma que a soberania do povo e a liberdade de imprensa são duas coisas correlatas.

Para resumir, entende ele que 
La fondatezza, la correttezza e la completezza dell informazione pubblica sono dunque essenziali così alla trasparenza, alla legalità, alla rappresentatitività e alla responsabilità dei pubblici poteri, come al controllo popolare e all'esercizio consapevole del diritto di voto. (FERRAJOLI, 2007, p. 420)

Por isso, reivindica a constitucionalização das garantias do máximo acesso possível (tanto ativo quanto passivo) à informação e à comunicação políticas. (FERRAJOLI, 2007, p. 421)

Pode-se concluir então que, a partir de uma perspectiva garantista, o direito fundamental à informação (correlativo à transparência governamental, materializado no princípio/dever de publicidade administrativa) é uma imposição do constitucionalismo democrático que está a exigir a construção do máximo de garantias para possibilitar o pleno acesso dos cidadãos às ações e informações estatais.

Vistas as precedentes abordagens teóricas sobre a dicotomia transparência/segredo, no seio da tradição político-jurídica ocidental, cabe agora examinar o tratamento normativo dessa dicotomia em alguns ordenamentos jurídicos, tomados aqui como referência, bem assim no ordenamento brasileiro, tanto do ponto de vista diacrônico quanto sincrônico.

\section{A Lei de Acesso de 2011}

Em consequência, em novembro de 2011 é publicada a Lei n. 15.527, que especificamente regula e garante o direito fundamental de acesso. Essa Lei apresenta inovações importantes, tais como:

a) constitui em sujeitos passivos - obrigados, portanto, a oferecer informações - não só as entidades da Administração direta e indireta no âmbito dos três poderes, como também as entidades privadas sem fins lucrativos que recebam verbas ou subvenções do poder público, na proporção desses recebimentos (art. $2^{\circ}$, par único); 
b) determina a divulgação espontânea, ou seja, independentemente de solicitação, de informações de interesse público, pelas mesmas entidades acima referidas (art. $\left.3^{\circ}, \mathrm{II}\right)$;

c) enfatiza a utilização dos meios eletrônicos de comunicação (internet), para a divulgação das informações, obrigando os órgãos a disponibilizar suas informações na rede mundial de computadores $\left(\operatorname{art} .8^{\circ}, \S 2^{\circ}\right.$ );

d) estabelece procedimento singelo para obtenção das informações pelos administrados, erigindo a CGU em órgão recursal, e ainda dispondo que, das decisões denegatórias por parte desta última, caberá recurso à Comissão Mista de Reavaliação de Informações prevista no artigo 35, cuja composição ficará delineada em Regulamento.

Já no que diz respeito às informações sigilosas, cuida a lei de:

a) vedar a denegação de prestação de informações que digam respeito à proteção de direitos fundamentais;

b) estabelecer como passíveis de classificação informações que possam:

I - pôr em risco a defesa e a soberania nacionais ou a integridade do território nacional;

II - prejudicar ou pôr em risco a condução de negociações ou as relações internacionais do País, ou as que tenham sido fornecidas em caráter sigiloso por outros Estados e organismos internacionais;

III - pôr em risco a vida, a segurança ou a saúde da população;

IV - oferecer elevado risco à estabilidade financeira, econômica ou monetária do País;

$\mathrm{V}$ - prejudicar ou causar risco a planos ou operações estratégicos das Forças Armadas;

VI - prejudicar ou causar risco a projetos de pesquisa e desenvolvimento científico ou tecnológico, assim como a sistemas, bens, instalações ou áreas de interesse estratégico nacional; 
VII - pôr em risco a segurança de instituições ou de altas autoridades nacionais ou estrangeiras e seus familiares; ou

VIII - comprometer atividades de inteligência, bem como de investigação ou fiscalização em andamento, relacionadas com a prevenção ou repressão de infrações. (art. 23)

c) estabelecer como graus de sigilo e respectivos prazos de desclassificação as espécies de informação ${ }^{21}$;

d) determinar revisão periódica, por parte da Comissão Mista de Reavaliação de Informações, das informações sigilosas, pelo prazo máximo de 4 anos. Após esgotado o prazo, as informações serão automaticamente desclassificadas (art. $35, \S \S 3^{\circ}$ e $4^{\circ}$ );

e) prever a reavaliação, por parte de órgãos e entidades públicas, dos atuais graus de sigilo dos seus documentos, no prazo máximo de dois anos a contar do início da vigência da lei (art. 39).

Por último, estabelece a lei uma vacatio de seis meses, passando a entrar em vigor no mês de maio de 2012.

Nesse mesmo mês, o Governo Federal edita o Decreto n. 7.724/12, que regulamenta a Lei de Acesso, detalhando as ações a serem empreendidas para maximizar a garantia do direito fundamental de que trata. Dentre as ditas ações, merece destaque a determinação para que os órgãos públicos estampem a remuneração de seus servidores (art. $\left.7^{\circ}, \S 3^{\circ}, \mathrm{VI}\right)$, o que causou alguma divergência no Judiciário, com a prolação de algumas liminares visando ao impedimento de tal publicação, sob o argumento de violação da intimidade dos agentes públicos ${ }^{22}$.

21 I) Ultrassecreta, com prazo máximo de desclassificação de 25 anos, renovável motivadamente pela Comissão Mista antes referida por prazo igual uma única vez;

II) secreta, com prazo de desclassificação de 15 anos; e

III) reservada, com prazo de 5 anos (art. $24, \S 1^{\circ}$ ).

22 Estatui a norma referida: $\S 3$ o Deverão ser divulgadas, na seção específica de que trata o $\S 1^{\circ}$, [internet] informações sobre:

$[\ldots]$

VI - remuneração e subsídio recebidos por ocupante de cargo, posto, graduação, função e emprego público, incluindo auxílios, ajudas de custo, jetons e quaisquer outras vantagens pecuniárias, bem como proventos de aposentadoria e pensões daqueles que estiverem 
Outro aspecto que merece destaque - dessa vez negativo - o Decreto diz respeito à Comissão Mista de Reavaliação de Informações. Com efeito, a norma determina que tal Comissão seja composta exclusivamente por Ministros de Estado ou titulares de Secretarias com status equivalente (art. 46). Em face do fato de ser a Comissão o órgão máximo em matéria de classificação/desclassificação documental, bem como na decisão de recursos nessa área, melhor seria ter decidido o Governo por uma comissão composta também por membros do Ministério Público, Legislativo e representantes de setores acadêmicos, tal como historiadores.

De qualquer sorte, tanto a Lei de Acesso quanto o seu Regulamento representa um tremendo avanço rumo à transparência administrativa, ao determinar uma nova relação entre governantes e governados. Reafirma-se assim a visão instrumental do Estado de Direito, subordinado que deve estar aos valores, bens e interesses julgados superiores pela sociedade.

\section{O Direito de Acesso na Esfera Ambiental}

A Lei n. 6.938/81, que dispõe sobre a Política Nacional do Meio Ambiente, tem dentre seus objetivos principais a divulgação de dados e informações ambientais. Isso em razão de que é por meio do acesso à informações que se torna possível a formação de uma consciência pública sobre a esfera do ambiente.

Nesse sentido, a Convenção sobre acesso à Informação, Participação pública em processos decisórios e Acesso à justiça em Temas Ambientais (também conhecida como Convenção de Aarhus), de junho de 1998, considera como informação ambiental todo e qualquer dado apresentado sob a forma escrita, oral, verbal, etc., sobre a condição de elementos ambientais, locais que sejam de interesse natural e paisagístico,

na ativa, de maneira individualizada, conforme ato do Ministério do Planejamento, Orçamento e Gestão;

Pelo que se lê, totalmente legítima a interpretação que valida o acesso aos nomes dos servidores, pois que outra não é a intenção da lei senão propiciar o conhecimento da remuneração dos funcionários de maneira individualizada. 
aspectos de diversidade biológica, e todas as indicações que possam afetar a tomada de decisões que tenham caráter ou interesse ambiental.

A Conferência das Nações Unidas sobre o Meio Ambiente e Desenvolvimento (Rio 92) trouxe, dentre seus documentos, a chamada Declaração do Rio sobre meio ambiente e desenvolvimento. Pode-se verificar em seu texto uma preocupação no sentido de fomentar a participação dos cidadãos nos processos de decisão em matéria ambiental, ao afirmar que a melhor forma de se tratar de aspectos ambientais é assegurar a participação dos interessados ${ }^{23}$. Para tanto, estabelece a necessidade do Estado em facilitar e estimular a participação e, dispondo para todos, as informações sem barreiras. E ainda sobre o processo de facilitação das informações, há que se destacar o disposto na Agenda 21 que estabelece que os Estados e as organizações internacionais busquem o fortalecimento dos sistemas de informações em setores relacionados ao desenvolvimento sustentável, destacando as possibilidades de transformações das informações já existentes em mecanismos úteis para a orientação e tomada de decisões para os indivíduos ${ }^{24}$.

O fundamento para essas disposições está na consideração do direito à informação como um direito humano. Isso demonstra o caráter fundamental desse direito, no sentido de ser ele essencial para o exercício da cidadania e fortalecimento das esferas democráticas. Tão somente com a disponibilidade de informações é que indivíduos e organizações podem participar nos processos dialógicos acerca das questões mais diversas.

\footnotetext{
23 "Princípio 10: A melhor maneira de tratar as questões ambientais é assegurar a participação, no nível apropriado, de todos os cidadãos interessados. No nível nacional, cada indivíduo terá acesso adequado às informações relativas ao meio ambiente de que disponham as autoridades públicas, inclusive informações acerca de materiais e atividades perigosas em suas comunidades, bem como a oportunidade de participar dos processos decisórios. Os Estados irão facilitar e estimular a conscientização e a participação popular, colocando as informações à disposição de todos. Será proporcionado o acesso efetivo a mecanismos judiciais e administrativos, inclusive no que se refere à compensação e reparação de danos.", disponível em <http://www.onu.org.br/rio20/img/2012/01/rio92. pdf $>$, acesso em abril de 2013.

24 Conforme Agenda 21, disponível em < http://www.mma.gov.br/responsabilidadesocioambiental/agenda-21/agenda-21-global>, acesso em abril de 2013.
} 
No caso da legislação brasileira, a Constituição Federal garante a todo e qualquer cidadão o direito de receber dos órgãos públicos informações, sejam elas referentes a questões particulares ou de interesse coletivo, respeitadas aquelas onde se deve manter sigilo em razão de disposição legal $^{25}$.

As matérias ambientais, além de serem reguladas por esse dispositivo constitucional, encontram diretriz específica na Lei n. 10.650, de 16 de abril de 2003, que trata do acesso público a dados e informações de ordem ambiental existentes nos órgãos e entidades integrantes do Sisnama (Sistema Nacional do Meio Ambiente). Essa lei dispõe sobre o acesso público aos dados e informações ambientais existentes nos órgãos e entidades integrantes do Sistema Nacional do Meio Ambiente (Sisnama), in verbis:

\begin{abstract}
Art. $2^{\circ}$ Os órgãos e entidades da Administração Pública, direta, indireta e fundacional, integrantes do Sisnama, ficam obrigados a permitir o acesso público aos documentos, expedientes e processos administrativos que tratem de matéria ambiental e a fornecer todas as informações ambientais que estejam sob sua guarda, em meio escrito, visual, sonoro ou eletrônico, especialmente as relativas a:

I - qualidade do meio ambiente;

II - políticas, planos e programas potencialmente causadores de impacto ambiental;

III - resultados de monotoramento e auditoria nos sistemas de controle de poluição e de atividades potencialmente poluidoras, bem como de planos e ações de recuperação de áreas degradadas;

IV - acidentes, situações de risco ou de emergências ambientais;
\end{abstract}

\footnotetext{
25 "Art. $5^{\circ}$ Todos são iguais perante a lei, sem distinção de qualquer natureza, garantindose aos brasileiros e aos estrangeiros residentes no País a inviolabilidade do direito à vida, à liberdade, à igualdade, à segurança e à propriedade, nos termos seguintes: $[\ldots]$

XXXIII - todos têm direito a receber dos órgãos públicos informações de seu interesse particular, ou de interesse coletivo ou geral, que serão prestadas no prazo da lei, sob pena de responsabilidade, ressalvadas aquelas cujo sigilo seja imprescindível à segurança da sociedade e do Estado".
} 
V - emissões de efluentes líquidos e gasosos, e produção de resíduos sólidos;

VI - substâncias tóxicas e perigosas;

VII - diversidade biológica;

VIII - organismos geneticamente modificados.

A Lei estabelece, ainda, que qualquer indivíduo, de modo independente de interesse específico, tem o direito a requerer as informações que tratam desta legislação. Tais dados devem ser informados ao requerente num prazo de 30 dias, contados da data do pedido. Importante destacar também que não somente a população pode fazer requerimento de informações, mas também as autoridades públicas podem exigir periodicamente informações de entidades privadas acerca de potenciais impactos ambientais envolvidos em suas atividades.

\section{Conclusão}

Examinado o segredo na política a partir de alguns de seus teorizadores e críticos, passa-se, nesta parte final, a tecer algumas considerações a partir das reflexões que a pesquisa realizada ensejou.

No quadro de monopolização de poder dos Estados Moderno e Contemporâneo, opera-se um processo de separação do público e do privado. Por um lado, a vida cotidiana do cidadão passa a dizer respeito somente a ele próprio, desde que no recesso de sua intimidade. Daí consagrarem-se os direitos de liberdade, tais como os estampados na Constituição brasileira no seu artigo $5^{\circ}$.

Paralelamente, e como reflexo da maior participação dos cidadãos na formação da vontade política governamental, dá-se o processo de publicização do poder. Agora, o que é público (não privado), deve ser exercido no meio do público (não secreto). O controle do poder, regra paradigmática das modernas Democracias representativas, somente pode ter lugar quando os cidadãos têm acesso às práticas governamentais. Assim, o aces- 
so do grande público ao conhecimento das ações do governo constitui-se em pilar fundamental para a estruturação de um regime democrático.

Dessa forma, ações consequentes com o princípio da publicidade na política têm sido implementadas através de normas jurídicas em diversos países democráticos. Embora o processo de publicização encontre limites - nas legislações encontra-se a barreira dos "Segredos de Estado em nome da Segurança Nacional" - é inegável que um tremendo esforço está em desenvolvimento em busca da transparência. Assim, no Brasil, têm surgido normas, como as antes referidas, e mecanismos, como os Portais da Transparência, e organizações, como a Transparência Brasil, todos inclinados a combater a opacidade. Mas essa luta está longe de ser vencida.

Na verdade, a tendência de generalização do segredo na Administração Pública parece derivar da resistência do poder tradicional, entendido como aquele que vê a política como coisa privada. A propria ideia habermasiana de "Estado neo-mercantilista" parece indicar essa forte tendência. (HABERMAS, 1984, p. 269)

De qualquer forma, a ideia de "Razão de Estado", já apontada por Schmitt, como doutrina que embasa a ação paternalista do governo sobre os súditos, solapa a ideia democrática. Como consequência de uma separação entre a ética e a política (os "imperativos morais" do Estado são distintos daqueles dos cidadãos) tornou-se nefasta pela sua hipertrofia.

Assim, a luta pela transparência representa, em última análise, uma tentativa de recuperar uma dimensão ética para a política, afastando a ideia de que a finalidade do Estado seja outra que não a de propiciar o estabelecimento de garantias para os direitos fundamentais estampados em suas Cartas fundacionais ${ }^{26}$.

A esfera ambiental acaba por enfatizar tal luta por transparência, não apenas no que se refere aos entes públicos, mas também privados, constituindo outra perspectiva de se ver a questão das razões de Estado.

\footnotetext{
26 Sobre uma concepção instrumental do Estado como aparato político a serviço dos valores, bens e interesses considerados superiores pela sociedade, ver Ferrajoli (1995, p. 13-14).
} 


\section{Referências}

AGENDA 21. [2013].Disponível em: < http://www.mma.gov.br/ responsabilidade-socioambiental/agenda-21/agenda-21-global $>$. Acesso em: $1^{\circ}$ abr. 2013.

ALMINO, João. O Segredo e a informação. Ética e política no espaço público. São Paulo: Brasiliense, 1986.

ARENDT, Hannah. Entre o passado e o futuro. Tradução M. B. Almeida. São Paulo: Perspectiva, 1972. 352p.

. Homens em tempos sombrios. Tradução D. Boltmann. São Paulo: Cia das Letras, 1987. 249 p.

Crisis de la República. Traducción G. Solanda. Madrid: Taurus, 1973. $234 \mathrm{p}$.

ARENDT, H. O Sistema totalitário. Tradução R. Raposo. Lisboa: Dom Quixote, 1978.622 p.

BOBBIO, Norberto. O Futuro da democracia: uma defesa das regras do jogo. Tradução M. A. Nogueira. Rio de Janeiro: Paz e Terra, 1986a. p.83-106.

. As Ideologias e o poder em crise. Tradução J. Ferreira.

Brasília, DF: UnB/Polis, 1988.

. Estado, governo, sociedade: para uma teoria geral da política. Tradução M. A. Nogueira. Rio de Janeiro: Paz e Terra, 1987. p. 55-134.

La Crisis de la democracia y la lección de los clásicos. In: ARENDT, Hannah; PONTARA, Giuliano; VECA, Salvatore. Crisis de la democracia. Traducción J. Marfá. Barcelona: Ariel, 1985. p. 5-25.

. Qual socialismo? Debate sobre uma alternativa. Tradução I. Freazza. Rio de Janeiro: Paz e Terra, 1983.

BRASIL. Decreto n. 7.724/12, de 16 de maio de 2012. Disponível em: <www.planalto.gov.br>. Acesso em: $1^{\mathrm{o}}$ jun. 2012.

Lei n. 15.527, de 18 de novembro de 2011. Disponível em:

<www.planalto.gov.br>. Acesso em: $1^{\mathrm{o}}$ jun. 2012. 
. Lei n. 6.938/81, de 31 de agosto de 2001. Disponível em:

<www.planalto.gov.br>. Acesso em: $1^{\mathrm{o}}$ jun. 2012.

. Lei n. 10.650, de 16 de abril de 2003. Disponível em: <www. planalto.gov.br>. Acesso em: $1^{\mathrm{o}}$ abr. 2013.

CANELA, G.; NASCIMENTO, S. (Coord.). Acesso à informação e controle social das políticas públicas. Brasília, DF: ANDI; ARTIGO 19, 2009.

DECLARAÇÃO do Rio sobre meio ambiente e desenvolvimento. [2013]. Disponível em: <http://www.onu.org.br/rio20/img/2012/01/rio92.pdf>. Acesso em: $1^{\circ}$ abr. 2013.

FERRAJOLI, Luigi. Derecho y razón: teoría del garantismo penal. Traducción P. Andrés Ibañez et.al. Madrid: Trotta, 1995. 991 p.

. Principia Iuris. Bari: Laterza, 2007. v. 2, 951 p.

HABERMAS, Jurgen. Mudança estrutural na esfera pública. Tradução F. Kothe. Rio de Janeiro: Tempo Brasileiro, 1984. 398 p.

LAFER, Celso. A Reconstrução dos direitos humanos: um diálogo com o pensamento de Hannah Arendt. São Paulo: Cia das Letras, 1988.

MENDEL, T. Freedom of information: a comparative legal survey. 2 . ed. Paris: UNESCO, 2008.

PISTONE, S., verbete Razão de Estado. In: BOBBIO, N. et al. Dicionário de política. Tradução João Ferreira et al. Brasília, DF: UnB, 1986. p. 1.066-1.073.

SCHMITT, Carl. La Dictadura. Traducción J. D. García. Madrid: Revista de Occidente, 1968. 338 p.

WEBER, Max. Economía y sociedad. Traducción J. M. Echavarría et al. México: Fondo de Cultura Económica, 1984. 
Sergio Urquhart de Cademartori é Doutor em Direito pela Universidade Federal de Santa Catarina (UFSC). Professor do Programa de Pós-Graduação em Direito da Universidade de Caxias do Sul (UCS).E-mail: scademartori@uol.com.br. Endereço profissional: Rua Francisco Getúlio Vargas, n. 1.130, Caxias do Sul, RS. CEP: 95070-560.

Caroline Ferri é Doutora em Direito pela Universidade Federal de Santa Catarina (UFSC). Professora do Programa de Pós-Graduação em Direito da Universidade de Caxias do Sul (UCS).E-mail: carolineferri@gmail.com.

Endereço profissional: Rua Francisco Getúlio Vargas, n. 11130. Caxias do Sul, RS. CEP: 95070-560. 